\title{
EOCENE (GREEN RIVER) FOSSIL INSECTS FROM PICEANCE CREEK BASIN, COLORADO
}

PRIBYL*, Louis J.; National Museum of Natural History, Department of Paleobiology, Washington, D.C. 20560, U.S.A.; LABANDEIRA, Conrad C.; National Museum of Natural History, Department of Paleobiology, Washington, DC 20560, U.S.A.; and KOHLS, D., Colorado Mountain College, Rifle Campus, Rifle, CO 81650, U.S.A.

The Smithsonian's National Museum of Natural History currently has assembled approximately 12,000 fossil insects and insect-damaged plants from east-central Colorado, collected by David Kohls. This collection represents six separate localities from the Parachute Creek Member of the Green River Formation, occurring in the southwestern portion of the Piceance Creek Basin. Each of these localities appears to be stratigraphically and temporally distinct. While this ongoing and expanding collection is being curated by locality, the collection is primarily an ecological one (sensu Gregory and Chase, 1992) since it includes all encountered fossil insects and plants, regardless of taphonomic condition, including entire and partial specimens of insects and leaves. The collection is secondarily arranged taxonomically, with taxa from each locality subdivided by order and family.

There are two distinct entomological elements to this collection. Insect body fossils constitute the first element. These insect fossils are frequently carbon impressions occurring in marlstone and occasionally in oil shale. Site-specific variations on this theme provide several taphonomic modes of preservation, including limonitization, microcrystalline pyritic replacement, and apparent presence of original chitin. In some instances, there has been retention of original light-and-dark patterning on elytra and membranous wings. Significantly, the taphonomic style of Piceance Basin insects is different from the classic localities of Lake Gosiute and Fossil Lake in Wyoming in that preservation is more threedimensional, and finer surface detail generally can be recognized. Strengths of this collection include the following taxa: Nematocera, especially Tipulidae (Diptera), Curculionoidea (Coleoptera), Auchenorrhyncha (Hemiptera), and Gryllidae (Orthoptera). Descriptions of the type of preservation and determinations of the numbers of insects representing orders and families at each locality are being made. Abundances for the Old Mountain site are as follows, and are generally representative of the other sites as well.

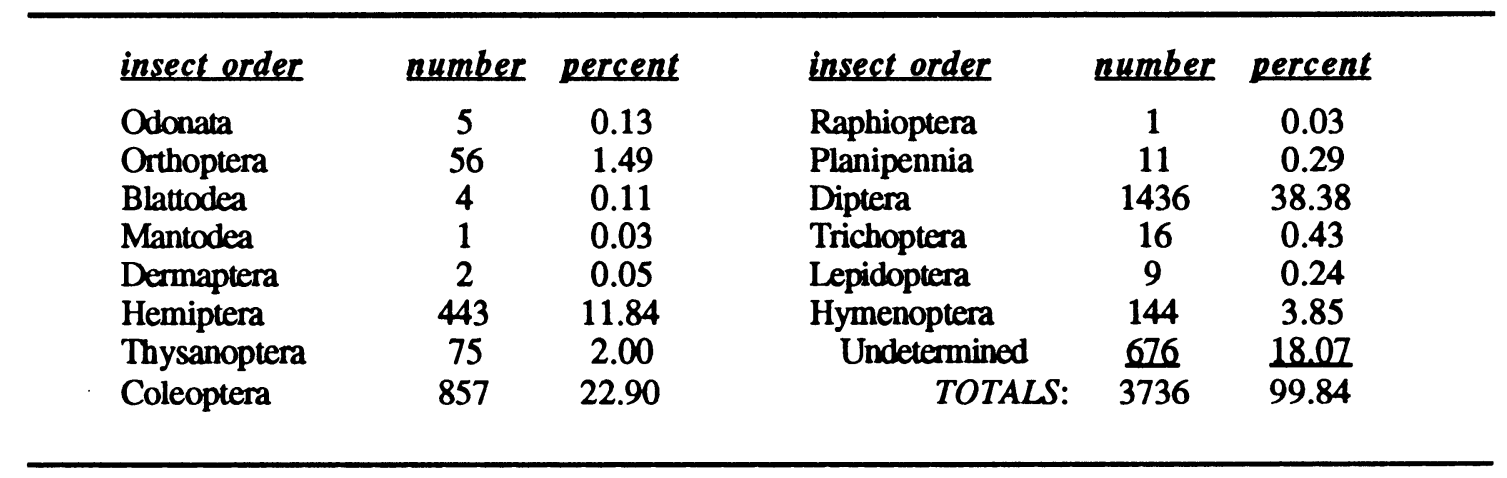

The second element is plant material containing evidence of insect herbivory. High numbers of leaves, seeds, and other plant parts occurring at each locality reveal both angiosperm plant hosts and their insect herbivores, many of which may be assignable to modern genera. Thus trace fossils of leaf miners, gallers, and highly stereotyped external feeders may be useful for establishing minimum dates for well-documented modern interactions.

This announcement highlights the availability of this collection to entomologists and other specialists interested in identifying and studying these insect fossils. The abundance, diversity, and exceptional quality of these insect fossils makes this collection a unique opportunity to explore insect systematics, terrestrial arthropod taphonomy, plant-insect interactions, and other aspects of insect paleobiology. 